\title{
Prediction of vertical permeability and reservoir anisotropy using coring data
}

\author{
Shedid A. Shedid ${ }^{1}$
}

Received: 19 April 2018 / Accepted: 11 January 2019 / Published online: 22 February 2019

(c) The Author(s) 2019

\begin{abstract}
Most reservoirs have different degrees of permeability anisotropy. Optimization of recovery is crucially dependent on the reservoir quality and anisotropy. The ratio of vertical and horizontal permeability is important when reservoir anisotropy $\left(K_{\mathrm{v}} / K_{\mathrm{h}}\right)$ and heterogeneity cannot be neglected. Therefore, an accurate knowledge of vertical and lateral permeability distribution is essential for better reservoir characterization. This work uses routine core data for analysis to develop new correlations and characterization of a sandstone reservoir under development. The two main goals of this study are to use core data to (1) develop correlations capable of predicting vertical permeability from horizontal permeability or mean hydraulic radius and (2) develop another correlation capable of predicting the permeability anisotropy ratio $\left(K_{\mathrm{v}} / K_{\mathrm{h}}\right)$ using effective porosity data. To accomplish the objectives of this project, various petrophysical properties were experimentally measured for 112 core samples extracted from an actual sandstone reservoir. The measurements included vertical permeability, horizontal permeability, effective porosity and saturations of oil and water. Applications of the developed results of this study help enhancing the prediction of vertical permeability, improving reservoir characterization and providing better simulation studies.
\end{abstract}

Keywords Vertical permeability $\cdot$ Anisotropic reservoir $\cdot$ Core data $\cdot$ Sandstones

\section{Nomenclature}

$A_{1,} B_{1} \quad$ Curve fitting constants

$F_{\mathrm{s}} \quad$ Shape factor

$K \quad$ Absolute permeability, md

$K_{\mathrm{h}} \quad$ Horizontal permeability, md

$K_{\mathrm{v}} \quad$ Vertical permeability, md

RQI Reservoir quality index, $\mu \mathrm{m}$, micron

RCA Routine core analysis

SCAL Special core analysis

$S_{\mathrm{gv}} \quad$ Surface area per unit grain volume, $\mu \mathrm{m}^{-1}$

$S_{\mathrm{w}} \quad$ Water saturation, fraction

$\varphi_{\mathrm{e}} \quad$ Effective porosity, fraction

$\tau \quad$ Tortuosity

\section{Subscripts}

e Effective

gr Grain

w Water

irr Irreducible

Shedid A. Shedid

shedid2020@yahoo.com

1 American University in Cairo (AUC), Cairo, P O. 11837, Egypt

\section{Introduction and literature review}

In early studies of reservoir engineering, the reservoirs are assumed to be homogeneous, isotropic and uniform. Absolute rock permeability $(K)$ is defined as the ability of the rock to transmit fluid(s). Horizontal permeability $\left(K_{\mathrm{h}}\right)$ is parallel to bedding plan and is generally greater than vertical $\left(K_{\mathrm{v}}\right)$. Low vertical permeability creates a larger pressure drop near the wellbore and directly affects the skin factor.

Vertical permeability is essential in reservoir management and development such as, the optimal well locations and production rate, horizontal well applications, completion optimization and perforation design, and planning EOR injectors/producers (Clark 1969; Zahaf and Tiab 2002).

The ratio of vertical to horizontal permeability $\left(K_{\mathrm{v}} / K_{\mathrm{h}}\right)$ represents the contrast in permeability between the vertical and horizontal planes within a formation (called anisotropic permeability). This ratio is important in reservoir simulation studies, because it is applicable in vertical wells and more important in partially penetrated or horizontal wells. In layered reservoirs, the vertical permeability of each layer is quite different from the surrounding layers. Therefore, these type of reservoirs are divided into layers based on the $\left(K_{\mathrm{v}} / K_{\mathrm{h}}\right)$ relationships. 
Clark (1969) indicated that the horizontal permeability $\left(K_{\mathrm{h}}\right)$ would be higher than the vertical one for large and flat rock grains. He concluded that generally, vertical permeability is lower than horizontal permeability, especially, if the sand grains are small and have irregular shape. Majority of petroleum reservoirs are in this category.

Prediction of permeability accurately enough from core and well $\log$ s have been achieved by several authors (Tiab 1993; Amaefule et al. 1993; Elkewidy 1996; Shedid Elgaghah 1997). They proposed methods for integrating core and $\log$ data for formation evaluation in term of flow units. To have a better reservoir description, we should consider the vertical variation of hydraulic properties. Osisanya et al. (1998) developed new permeability porosity correlations but without consideration of anisotropic conditions of the reservoirs.

Iheanacho et al. (2012) developed several correlations of vertical and horizontal permeability for sandstone and shaly sandstones reservoirs and made a general conclusion that vertical permeability decreases with depth. Fazelalav (2013) developed several correlations for prediction of vertical permeability for Arbuckle formation as shown in Table 1. However, these correlations suffer from poor correlating coefficients.

Correlations listed in Table 1 below indicates that vertical permeability may increase or decrease, but it does not have a general trend. Majority of other studies had confirmed a general conclusion that vertical permeability decreases with depth (Clark 1969; Osisanya et al, 1998; Zahaf and Tiab 2002; Iheanacho et al. 2012).

The main objective of this work is to develop semi-empirical correlations between vertical permeability and horizontal permeability for sandstone reservoirs. Actual core data are gathered and analyzed from an Egyptian sandstone reservoir to achieve this goal.

\section{Development of vertical-horizontal permeability relationship using core data}

The factors affecting rock permeability have been recognized to include the size, form, and shape of grains constituting the reservoir rocks. Therefore, it is important to develop a relationship between microscopic level attributes and microscopic core data based on the concept of hydraulic mean radius. This is because the hydraulic mean radius considers variations in permeability and porosity as it is defined to be equal to $\sqrt{K / \varphi}$.

Recalling the modified Kozeny-Carman equation, Eq. (1) that is shown below:

$K=\left(\frac{\varphi_{\mathrm{e}}^{3}}{\left(1-\varphi_{\mathrm{e}}\right)^{2}}\right) \times\left[\frac{1}{F_{\mathrm{s}} \tau^{2} S_{\mathrm{gr}}^{2}}\right]$

It is possible to build a relationship between microscopic level attributes and microscopic core data. Dividing both sides of Eq. (1) by effective porosity $\left(\varphi_{\mathrm{e}}\right)$ and taking the square root of both sides results in:

$\sqrt{\frac{K}{\varphi_{\mathrm{e}}}}=\left(\frac{\varphi_{\mathrm{e}}}{\left(1-\varphi_{\mathrm{e}}\right)}\right) \times\left[\frac{1}{\sqrt{F_{\mathrm{s}}} \tau S_{\mathrm{gr}}}\right]$

Amaefule et al. (1993) introduced the concept of reservoir quality index (RQI) considering the pore throat, pore and grain distributions and other macroscopic parameters to come up with an equation of the reservoir quality index (RQI) as follows:

$\mathrm{RQI}(\mu \mathrm{m})=0.0324\left(\sqrt{\frac{K}{\varphi_{\mathrm{e}}}}\right)$

where RQI is the reservoir quality index (micron, $\mu \mathrm{m}$ ), $K$ is permeability (md) and $\phi$ is the effective porosity (fraction).

Zahaf and Tiab (2002) replaced absolute permeability $(K)$ by the horizontal one $\left(K_{\mathrm{h}}\right)$ in the RQI model, Eq. (3), and developed a general vertical permeability model as a function of hydraulic mean radius, as given below:

$K_{\mathrm{v}}=A_{1} \times\left(\sqrt{\frac{K_{\mathrm{h}}}{\varphi}}\right)^{B_{1}}$

where $A_{1}$ and $B_{1}$ are coefficients to be determined for a specific field case. $K_{\mathrm{v}}$ and $K_{\mathrm{h}}$ are vertical and horizontal permeability (md), respectively, and $\phi$ is the effective porosity (fraction).
Table 1 Developed vertical permeability correlations for Arbuckle formation (Fazelalav 2013)

\begin{tabular}{lllcl}
\hline$\#$ & Correlation & Correlating coefficient & \# Of cores & Application condition and core observation \\
\hline 1 & $K_{\mathrm{v}}=0.1871 K_{\mathrm{h}}$ & $R^{2}=0.5367$ & 216 & Rock without fractures \\
2 & $K_{\mathrm{v}}=0.1871 K_{\mathrm{x}}$ & $R^{2}=0.5367$ & 97 & For $K_{\mathrm{v}}$ is less than $K_{\mathrm{h}}$ \\
3 & $K_{\mathrm{v}}=2.4484 K_{\mathrm{h}}$ & $R^{2}=0.6916$ & 60 & For $K_{\mathrm{v}}$ is bigger than $K_{\mathrm{h}}$ \\
4 & $K_{\mathrm{v}}=82.624 K_{\mathrm{h}}$ & $R^{2}=0.9906$ & 18 & For $K_{\mathrm{v}}$ is much bigger than $K_{\mathrm{h}}$ due to \\
& & & extremely vertical fractures \\
\hline
\end{tabular}




\section{Field case study: Gulf of Suez, Egypt}

An oil field is located in the Gulf of Suez, Egypt. The field was discovered in the early 2000s with potential pay in the HL-R formation. This formation is characterized as a sandstone reservoir with multiple thin intervals of average thickness of 5' ft. Geological analysis of the HL-R sandstone rock showed that it contains glauconite, which usually occurs as green, amorphous grains seldom larger than fine sand size.

Reservoir characterization studies showed that the formation was a transgressive succession punctuated by surfaces of erosion and mainly dominated by estuarine and restricted marine deposits. The reservoir fluid in the HL-R reservoir is described as a volatile oil that may grade into black oil in the deeper portion of the reservoir. Data from vertical appraisal wells confirmed low production rates and low estimate ultimate recovery. This represented a challenge for the economic development to capture the reservoir heterogeneity in this formation.
The vertical well HL-R6 was selected as a part of an appraisal program for a coring study. This coring task provided 112 preserved cores, which were used for measuring vertical permeability, horizontal permeability, porosity, density and saturations of oil and irreducible water. The core samples were extracted from the producing formation and the average rock density of core was measured to be $2.66 \mathrm{~g} / \mathrm{cm}^{3}$. The laboratory measurements were conducted at COREX lab in Cairo, Egypt. The porosity was measured volumetrically, while permeability was measured with a conventional air permeameter, and the irreducible water saturation was determined by the porous plate method.

Table 2 presents data of only 30 samples for every $5 \mathrm{ft}$ of the cored zone, but the well was sampled every $1 \mathrm{ft}$ and 112 core data are selected and used in plots of this project.

The attained data of vertical permeability is plotted versus depth in Fig. 1 It shows a wide range of variation and a general decrease mode in vertical permeability with depth. Figure 1 reveals that vertical permeability at depths
Table 2 Routine core analysis (RCA) data for 30 core samples as an example of 112 core data used

\begin{tabular}{|c|c|c|c|c|c|c|}
\hline Core \# & Depth (ft) & Perm-H $\left[K_{\mathrm{h}}(\mathrm{md})\right]$ & $\operatorname{PermV}\left[K_{\mathrm{v}}(\mathrm{md})\right]$ & $\left(K_{\mathrm{v}} / K_{\mathrm{h}}\right)$ & Porosity, $\phi(\%)$ & Sw $(\%)$ \\
\hline 1 & 8700 & 99.70 & 56.10 & 0.057 & 13.20 & 06.50 \\
\hline 3 & 8705 & 42.10 & 31.00 & 0.736 & 12.80 & 07.50 \\
\hline 4 & 8710 & 12.80 & 12.30 & 0.961 & 11.10 & 03.70 \\
\hline 5 & 8715 & 1480.00 & 13.30 & 0.001 & 08.90 & 04.80 \\
\hline 6 & 8720 & 21.60 & 10.11 & 0.468 & 11.60 & 05.20 \\
\hline 7 & 8725 & 40.70 & 23.20 & 0.570 & 11.70 & 05.10 \\
\hline 8 & 8730 & 187.0 & 97.70 & 0.522 & 14.40 & 06.70 \\
\hline 9 & 8735 & 2274.0 & 2189.00 & 0.962 & 21.60 & 03.30 \\
\hline 10 & 8740 & 1967.0 & 378.00 & 0.192 & 17.20 & 05.20 \\
\hline 11 & 8745 & 1457.0 & 401.00 & 0.275 & 14.70 & 04.00 \\
\hline 12 & 8750 & 01.25 & 0.82 & 0.656 & 02.12 & 17.87 \\
\hline 13 & 8755 & 0.05 & 0.05 & 1.00 & 09.60 & 13.00 \\
\hline 14 & 8760 & 1634.00 & 0.04 & 0.00 & 21.40 & 03.00 \\
\hline 15 & 8765 & 0.05 & 0.05 & 1.00 & 19.10 & 04.00 \\
\hline 16 & 8770 & 1490.00 & 1080.00 & 0.725 & 21.40 & 10.03 \\
\hline 17 & 8775 & 0.08 & 0.06 & 0.750 & 18.80 & 02.00 \\
\hline 18 & 8780 & 0.05 & 0.04 & 0.800 & 01.70 & 05.00 \\
\hline 19 & 8785 & 184.00 & 0.00 & 0.000 & 19.10 & 10.50 \\
\hline 20 & 8790 & 151.00 & 0.04 & 0.001 & 18.10 & 05.00 \\
\hline 21 & 8795 & 176.00 & 120.00 & 0.682 & 15.40 & 04.00 \\
\hline 22 & 8800 & 368.00 & 332.00 & 0.902 & 18.80 & 09.00 \\
\hline 23 & 8805 & 12.40 & 2.94 & 0.237 & 01.40 & 05.00 \\
\hline 24 & 8810 & 192.00 & 88.80 & 0.462 & 13.70 & 04.40 \\
\hline 25 & 8815 & 427.00 & 11.00 & 0.258 & 13.40 & 13.20 \\
\hline 26 & 8820 & 61.10 & 47.70 & 0.780 & 14.30 & 03.50 \\
\hline 27 & 8825 & 150.00 & 114.00 & 0.760 & 17.50 & 07.00 \\
\hline 28 & 8830 & 86.00 & 0.05 & 0.000 & 18.30 & 04.00 \\
\hline 29 & 8835 & 2.48 & 1.09 & 0.439 & 02.40 & 03.00 \\
\hline 30 & 8840 & 563.00 & 668.00 & 1.186 & 20.20 & 02.00 \\
\hline
\end{tabular}




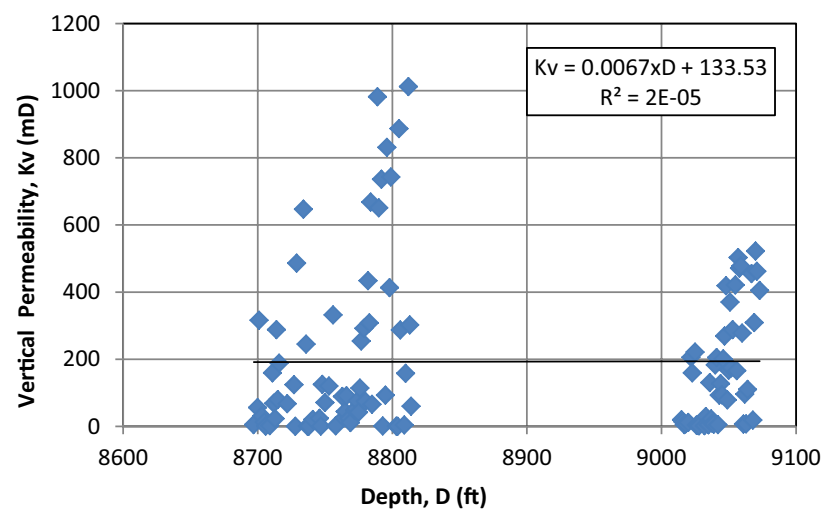

Fig. 1 Variation of vertical permeability with depth

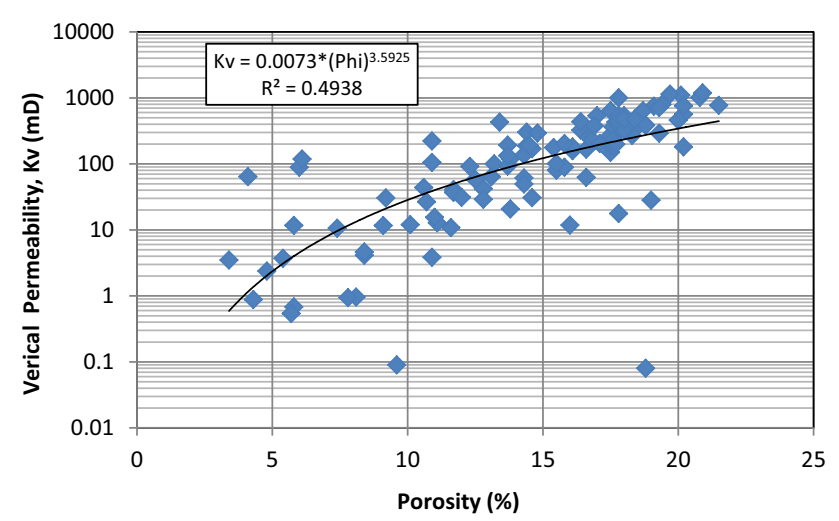

Fig. 2 Vertical permeability and porosity relationship

from 9000 to $9100 \mathrm{ft}$ is lower than others at depths from 8700 to $8800 \mathrm{ft}$.

Using all data points of 112 cores and plotting of vertical permeability versus porosity is shown in Fig. 2. This core data is used to develop the following empirical correlation:

$K_{v}=0.0073 \times \Phi^{3.5925}, \quad R^{2}=0.4938$

Additionally, a plot of horizontal permeability versus porosity is presented in Fig. 3 and a correlation is developed using curve fitting as shown below,

$K_{h}=0.0016 \times \Phi^{4.0146}, \quad R^{2}=0.5381$

A plot of vertical permeability versus a horizontal one using 112 core data is shown in Fig. 4 and yields the following new Eq. (7) for predicting vertical permeability;

$K_{\mathrm{v}}=0.7903 \times K_{\mathrm{h}}-3.431, \quad R^{2}=0.868$

Equation (7) represents a good tool for predicting vertical permeability with a good correlating coefficient $\left(R^{2}=0.868\right)$.

For the purpose of correlating the vertical permeability to the hydraulic mean radius, the same data points were plotted

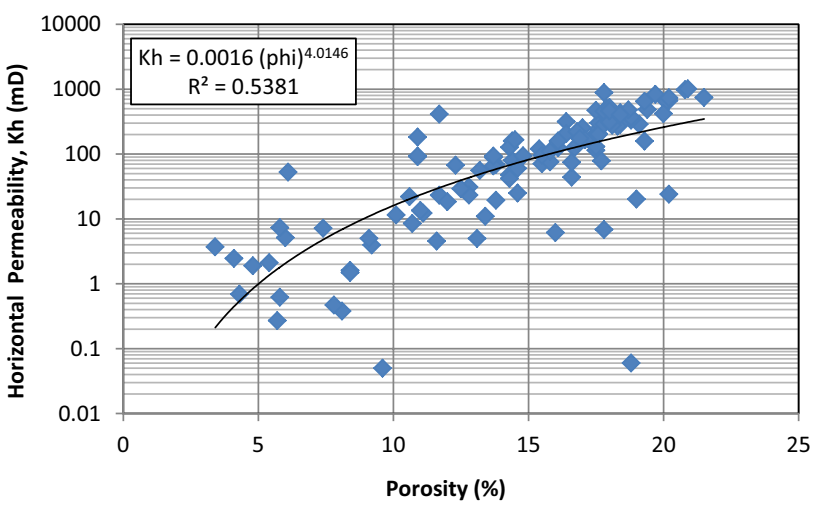

Fig. 3 Horizontal permeability and porosity relationship

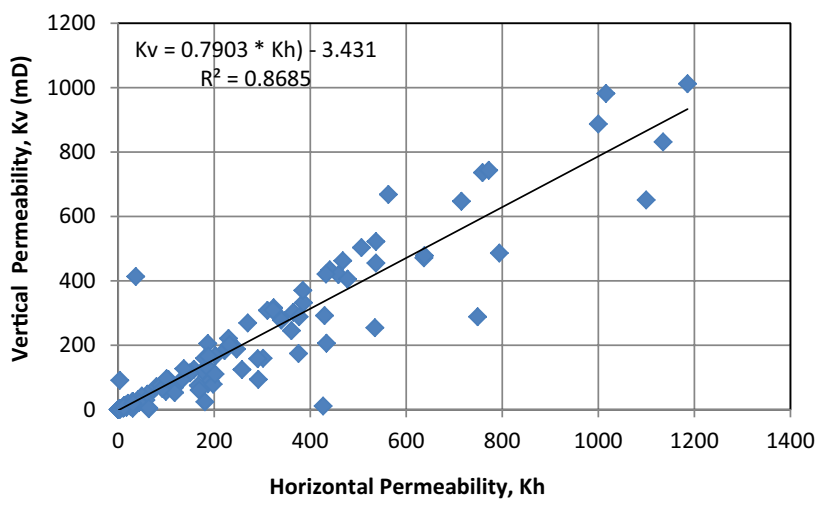

Fig. 4 Newly developed vertical-horizontal permeability relationship

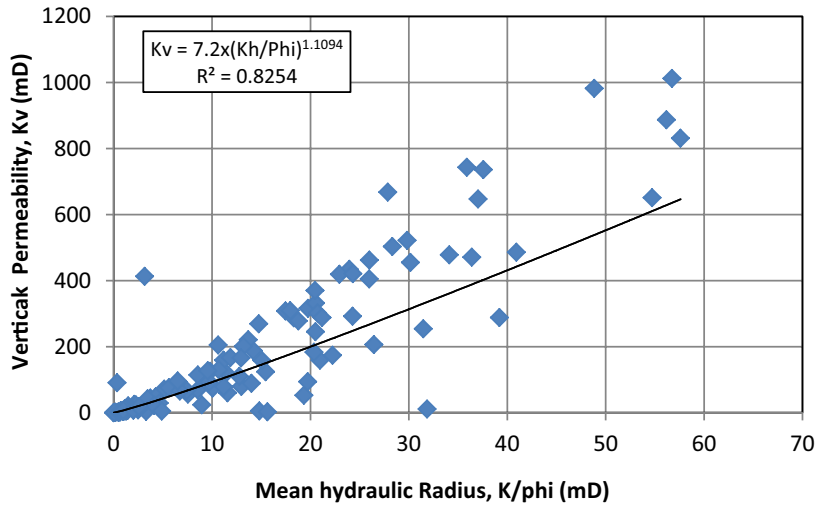

Fig. 5 A plot of vertical perm versus mean hydraulic radius

in Fig. 5. Applying the curving fitting technique provides the following correlation below,

$K_{\mathrm{v}}=7.2 \times\left(\sqrt{\frac{K_{\mathrm{h}}}{\varphi}}\right)^{1.1094}, \quad R^{2}=0.868$ 


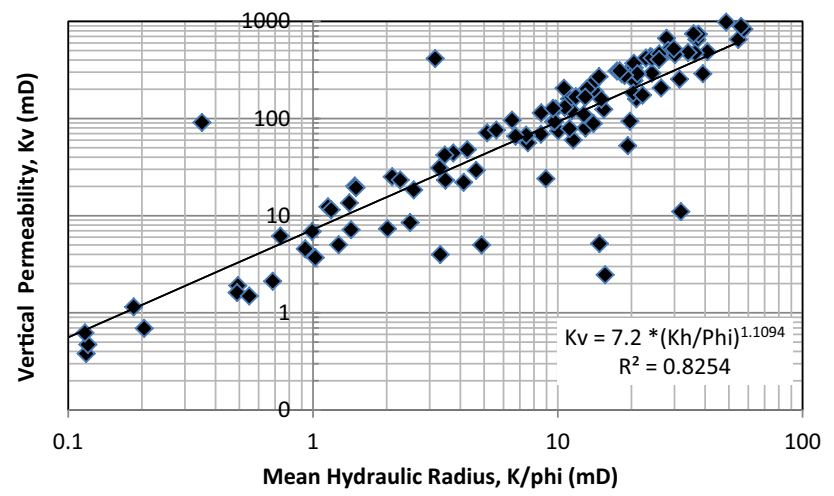

Fig. 6 Log-log plot of vertical permeability versus mean hydraulic radius

where $K_{\mathrm{v}}$ and $K_{\mathrm{h}}$ are vertical and horizontal permeability (md), respectively, and $\Phi$ is the effective porosity (fraction).

A $\log -\log$ plot of vertical permeability versus mean hydraulic radius is presented in Fig. 6 with a good correlating coefficient of 0.82 .

Rearranging Eq. (8) results in a correlation capable of predicting the anisotropic permeability ratio from porosity, as shown below,

$$
\frac{K_{\mathrm{v}}}{K_{\mathrm{h}}^{1.1094}}=\left(\frac{7.2}{\sqrt{\phi^{1.1094}}}\right)=\left(\frac{7.2}{\phi^{0.5547}}\right), \quad R^{2}=0.825
$$

The above equation indicates that the anisotropy ratio of permeability decreases with porosity for this sandstone reservoir. Equation (9) is important for reservoir simulation studies and may be used to predict the anisotropic ratio for more realistic results than that one attained from defaulted values in commercial software.

\section{Conclusions}

This study was undertaken to develop correlations capable of predicting vertical permeability and permeability anisotropy ratio using routine core data. The main conclusions of the study are summarized as follows:

1. Routine core data were gathered and used for the analysis and correlation of vertical permeability with horizontal permeability and other petrophysical properties of sandstone reservoir.

2. The permeability anisotropy ratio varies over a wide range of depth in sandstone reservoir under investigation. The variation exhibits a general decrease with depth.
3. New correlations were developed as tools capable of predicting vertical permeability from porosity, horizontal permeability and/or from mean hydraulic radius.

4. A correlation between anisotropic permeability ratio and porosity is developed and can be used to predict the anisotropic ratio from porosity core data.

5. The developed correlations represent useful tools for better studying reservoir management such as optimal well location, simulation studies and a better description of the reservoir.

Open Access This article is distributed under the terms of the Creative Commons Attribution 4.0 International License (http://creativeco mmons.org/licenses/by/4.0/), which permits unrestricted use, distribution, and reproduction in any medium, provided you give appropriate credit to the original author(s) and the source, provide a link to the Creative Commons license, and indicate if changes were made.

\section{References}

Amaefule JO, Altumbay M, Tiab D, Kersey D, Gt, Keelan DK (1993) Enhanced reservoir description: using core and log data to identify hydraulic (flow) units and predict permeability in uncored intervals/wells. In: SPE 26436 Presented at 68th Ann. Tech. Conf. Exhibit, Soc. Pet. Eng., Houston, 3-6 Oct 1993, pp 205-220

Clark NJ (1969) Elements of petroleum reservoirs, (revised ed). Soc. Pet; Eng., Dallas, Henry L. Dohery series, pp 19-30

Elkewidy TI (1996) Characterization of hydraulic flow units in heterogeneous clastic and carbonate reservoirs. In: PhD School of Petroleum and Geological Engineering, The University of Oklahoma, Norman

Fazelalav M (2013) The relation between vertical and horizontal permeability, Arbuckle formation, Wellington field, Kansas geological survey, open-file report, June 2013. http://www.kgs.ku.edu/ Publications/OFR/2015/OFR2015_25.pdf

Iheanacho P, Tiab D, Igbokoyi AO (2012) Vertical-horizontal permeability relationships for sandstone reservoirs, SPE paper 163011. In: Nigeria annual international conference and exhibition, 6-8 Aug 2012

Osisanya SO, Tiab D, Elgaghah SA (1998) In situ permeability-porosity relationship in clean formations. In: Annual technical meeting, 8-10 June, Alberta Petroleum Society of Canada, Calgary

Shedid- Elgaghah SA (1997) Influence of stress on the petrophysical properties in clean and shaly heterogeneous formation. $\mathrm{In}: \mathrm{PhD}$ School of Petroleum and Geological Engineering. The University of Oklahoma, Norman

Tiab D (1993) Modern core analysis, vol 1-theory. Core Laboratories, Houston

Zahaf K, Tiab D (2002) Vertical permeability from in situ horizontal measurements in shaly-sand reservoirs. J Can Pet Technol. https ://doi.org/10.2118/02-08-01

Publisher's note Springer Nature remains neutral with regard to jurisdictional claims in published maps and institutional affiliations. 